\title{
Basic Fuchsin
}

National Cancer Institute

\section{Source}

National Cancer Institute. Basic Fuchsin. NCI Thesaurus. Code C44332.

A green, crystalline, solid dye that is one of the major components of magenta. Basic fuchsin is primarily used for bacterial identification, but is also used as a dye in textiles, leather, and printing inks. Exposure to basic fuchsin is irritating to the eyes and skin. The substance is reasonably anticipated to be a human carcinogen. (NCI05) 